\title{
Increased pulmonary and intestinal permeability in Crohn's disease
}

\author{
A Adenis, J-F Colombel, P Lecouffe, B Wallaert, B Hecquet, X Marchandise, A Cortot
}

\begin{abstract}
We tested the hypothesis that an increased epithelial permeability may affect sites other than the intestine in patients with Crohn's disease by simultaneously evaluating their pulmonary and intestinal permeability. Pulmonary and intestinal permeability were measured by clearance of inhaled technetium$99 \mathrm{~m}$ diethylene triamine pentacetate $\left({ }^{99 m}\right.$ TcDTPA) and by urinary recovery of chromium51 ethylene diamine tetracetate respectively in 22 patients with Crohn's disease. The half time clearance of ${ }^{99 \mathrm{~m}}$ Tc-DTPA from lung to blood $(t 1 / 2 L B)$ was decreased - that is pulmonary permeability increased - in the whole group of patients with Crohn's disease as compared with 13 controls (median 45.5 minutes (8-160) $v 85$ minutes $(34-130)(p<0.003))$. When analysed separately only patients with active Crohn's disease $(n=15)$ had a decreased $t 1 / 2$ lung to blood $v$ controls (42 minutes $(8-160) v$ 85 minutes (34-130) $(p<0.0025))$. Among patients with active Crohn's disease, six were studied again when their disease was quiescent and their $t 1 / 2$ lung to blood did not differ significantly. The intestinal permeability was increased in the whole group of Crohn's disease patients as compared with 15 controls $\quad(5 \cdot 25 \% \quad(1 \cdot 2-24) \quad v \quad 1.7 \% \quad(0.65-5 \cdot 75)$ $(p<0.0002))$. When analysed separately both patients with active and inactive Crohn's disease had increased intestinal permeability $v$ controls $(8 \cdot 1 \%(1 \cdot 6-24)$ and $3.5 \%(1 \cdot 2 \cdot 9 \cdot 2) v$ $1.7 \%(0.65-5.75))(p<0.0001, p=0.05$ respectively). Six patients with active Crohn's disease were studied again when their disease was quiescent and their intestinal permeability decreased significantly $p<0.04)$. Pulmonary permeability was increased in patients with Crohn's disease but was not greatly influenced by Crohn's disease activity as opposed to intestinal permeability. The mechanism of this increase is unknown, but may be related in some patients to the presence of an alveolitis.
\end{abstract}

The aetiology of Crohn's disease remains unknown despite intensive research efforts. The current concept of the pathogenesis of Crohn's disease includes interactions between immunological abnormalities, environmental agents, and genetic influences. ${ }^{1-3}$ Increased intestinal permeability to luminal antigens could be one of the aetiologic factors. ${ }^{+5}$ Indeed, increased intestinal permeability has been described in Crohn's disease using various probes. ${ }^{5-15}$ Whether this abnormal permeability is a genetically determined, primary aetiologic factor, or a result of intestinal inflammation is not yet clearly estab- lished. ${ }^{5-7} 1617$ The finding by Hollander $e t a l^{5}$ that intestinal permeability was also increased in healthy relatives of patients with Crohn's disease could favour the genetic hypothesis, although this point remains controversial. ${ }^{16} 18 \mathrm{We}$ and others have previously shown by performing bronchoalveolar lavage that $50 \%$ of patients with Crohn's disease had a subclinical alveolitis - that is, subclinical accumulation of immune and inflammatory cells in the lower respiratory tract. ${ }^{19-21}$ Such a lymphocyte alveolitis is a well known feature in pulmonary sarcoidosis ${ }^{22}$ and is associated with an increased pulmonary permeability to diethylenetriaminepenta-acetate radiolabelled with $99 \mathrm{~m}$-technetium $\left({ }^{99 \mathrm{~m}} \mathrm{Tc}\right.$ DTPA). ${ }^{23}$ We thus hypothesised that pulmonary permeability might be altered in Crohn's disease as well and we undertook a prospective study of pulmonary permeability in patients with Crohn's disease, free of clinical pulmonary symptoms and with normal chest radiography.

\section{Methods}

\section{PATIENTS}

Twenty two patients with Crohn's disease were prospectively included in the study which was approved by the local Ethical Committee. None had a previous history of pulmonary disease or chest radiography abnormalities at the time of the study. None of the patients had ever smoked. Diagnosis of Crohn's disease was established by the usual clinical, radiological, endoscopic and histopathological findings. Clinical details relating to the patients are shown in Table I. Fifteen patients had active Crohn's disease - that is, Crohn's Disease Activity Index (CDAI) $\geq 150$ and seven patients had quiescent disease (CDAI $<150$ ) at the time of the study.

Pulmonary permeability and intestinal permeability were measured once in all the 22 patients.

TABLE I Clinical details of patients with Crohn's disease (expressed in median and range when necessary)

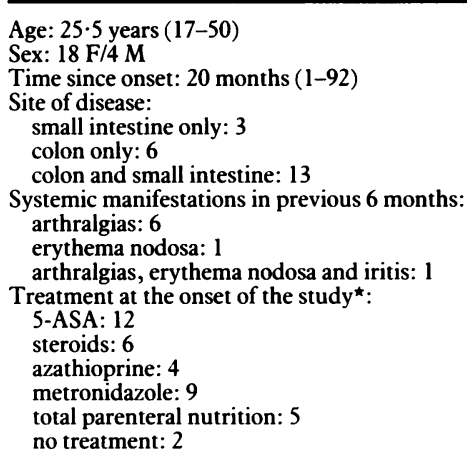

^Some patients were classified in more than one group. 
In six of 22 patients pulmonary permeability and intestinal permeability were measured first when active then one to seven months later when quiescent.

\section{CONTROL SUBJECTS}

Thirteen healthy volunteers (six women and seven men; median age 29 years, range 21 to 43 ) from the medical staff acted as controls for the pulmonary permeability test. None of the patients had ever smoked. Fifteen distinct healthy controls (four women and 11 men; median age 30 years, range 24-45) were tested for the ${ }^{51} \mathrm{Cr}$-EDTA 24 hour urinary excretion test.

All patients and controls gave their informed consent according to the Helsinki rules.

\section{MEASUREMENT OF PULMONARY ${ }^{99 \mathrm{~m}}$ TC-DTPA CLEARANCE}

This technique allows for determination of a non-invasive index related to lung permeability by measuring the lung to blood clearance of an inhaled radiolabelled molecule, the ${ }^{99} \mathrm{~m}$ TcDTPA. $^{2325}$

\section{Preparation of ${ }^{99 \mathrm{~m}} T c-D T P A$}

Sodium pertechnate $\left({ }^{99} \mathrm{mcO}_{4}^{-}\right)$was obtained by elution in isotonic saline from a ${ }^{99} \mathrm{Mo}$ generator (Tc-99-ELUMATIC III, International CIS). The chelation of ${ }^{99 \mathrm{~m}} \mathrm{Tc}$ by DTPA was made by introducing $1480 \mathrm{MBq}(40 \mathrm{mCi})$ of ${ }^{99} \mathrm{TcO}_{4}$ into a vial which contained, in a nitrogen atmosphere, $9.1 \mathrm{mg}$ of DTPA and $0.45 \mathrm{mg}$ of stannous chloride (TCK 6, International CIS). The vial was gently shaken for two minutes ${ }^{99 \mathrm{~m}}$ Tc-DTPA was immediately used or stored for less than one hour. Radiochemical purity of the chelate was assessed by paper chromatography using Whatman no 1 paper and a solvent of $240 \mu \mathrm{l}$ butanol, $240 \mu \mathrm{l}$ ethanol and $120 \mu \mathrm{l}$ water. The vial contained more than $99 \%$ of ${ }^{99 m}$ Tc-DTPA 90 minutes after preparation.

\section{Aerosol generation and administration}

The ${ }^{99 \mathrm{~m}}$ Tc-DTPA solution (1110 $\left.\mathrm{MBq}\right)$ was placed into a commercial jet nebuliser (VENTICIS II, International CIS). The aerosol was produced at an airflow rate of $8 \mathrm{l} /$ minutes. According to the manufacturer the mass section diameter was $0.8 \mu \mathrm{m}$ with a geometric standard deviation of $2 \cdot 1$. Patients were in the supine position with their backs against a gamma camera and their nose occluded. The aerosol was inhaled by quiet breathing through a mouthpiece for two minutes.

\section{Data acquisition}

Immediately after inhalation, gamma camera imaging was done using a large field scintillation camera (Acti camera, CGR) fitted with a parallel high resolution, low energy collimator and linked to a computer (Apex 009, Elscint). One minute frames were acquired in posterior view during 20 minutes. Matrix acquisition size was $128 \times 128$.

\section{Data processing}

A reference image, obtained by adding the five first images, was used for delineating the region of interest. A rectangular form was fitted as closely as possible over the right lung. A lower level of the maximum pixel counts was adjusted to define the outer border of the lung. We did not use a correction factor for vascular background as previous studies have suggested that this may not be necessary. ${ }^{26}{ }^{27}$ After correction for radionuclide decay, the activity measured was plotted versus time. A monoexponential fitting was carried out on the curve between the peak activity and the 10 minute point after the peak activity. This exponential curve allowed calculation of the half-time clearance - that is, the time for a $50 \%$ decrease from the peak activity of $99 \mathrm{mTc}$-DTPA from lung to blood $(\mathrm{t} t / 2 \mathrm{LB})$ expressed in minutes. The estimated radiation dose was smaller than $0 \cdot 2 \mathrm{mGy}$ to the whole body and $0.2 \mathrm{mGy}$ to the gonads.

\section{MEASUREMENT OF INTESTINAL ${ }^{51} \mathrm{Cr}$-EDTA CLEARANCE}

Intestinal permeability was assessed using ${ }^{51} \mathrm{Cr}$ labelled with ethylenediaminetetra acetic acid (EDTA) according to Bjarnason's technique. ${ }^{8}$ After an overnight fast, $3.7 \mathrm{MBq}(100 \mu \mathrm{Ci})$ ${ }^{51} \mathrm{Cr}-\mathrm{EDTA}$ (specific activity: 17 to $75 \mathrm{MBq} / \mathrm{mg}$, International CIS) was given orally and followed with $125 \mathrm{ml}$ of water. Urine was collected during 24 hours. Two hours after they drank the ${ }^{51}$ Cr-EDTA solution, subjects were allowed normal food and fluid intake, except for alcohol. Three $5 \mathrm{ml}$ samples of the pooled 24 hour urine collection were counted together with a $5 \mathrm{ml}$ sample of a 1:5000 dilution of the oral dose in a gamma counting system equipped with a $\mathrm{NaI}$ crystal (Gammamatic I, Kontron). Radioactivity excreted in the urine over the 24 hour period was expressed as the percentage of the total oral dose. The estimated delivered radiation dose was smaller than $0.05 \mathrm{mGy}$ to the whole body and $0.2 \mathrm{mGy}$ to the gonads.

\section{BRONCHOALVEOLAR LAVAGE}

In six patients with active Crohn's disease, bronchoalveolar lavage was performed after premedication with atropine under local anaesthesia with lignocaine using a wedged fibreoptic bronchoscope (Model BF-B3; Olympus Corp of America, New Hyde Park, NY, USA) and 250 $\mathrm{ml}$ sterile saline solution was applied in five $50 \mathrm{ml}$ aliquots with immediate gentle vacuum aspiration after each aliquot as previously described." Total number and differential cell count were determined in lavage fluid and compared with normal values from our laboratory. ${ }^{28} \geq 9$

STATISTICAL ANALYSIS

Results were presented as median value and lower and upper values and as mean value when necessary. Statistical analysis was performed using non-parametric tests. Differences between groups were assessed using the Mann-Whitney U-test for unpaired data and the Wilcoxon's rank sum test for paired data. The Spearman rank test 


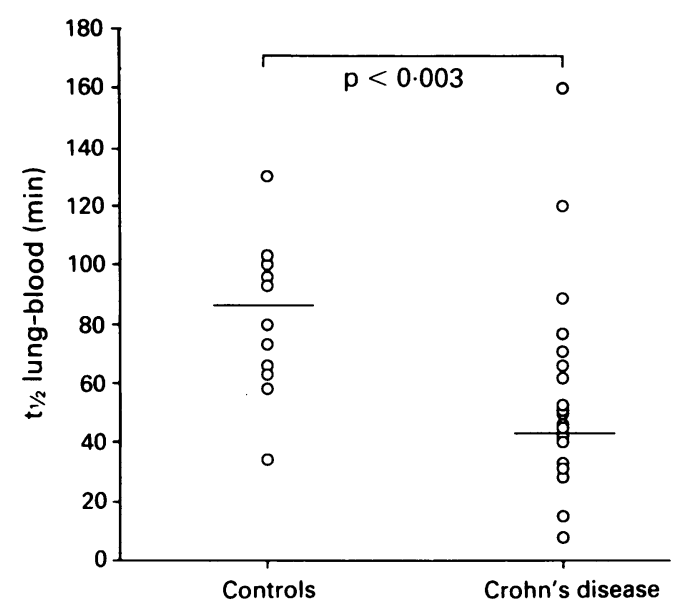

Figure 1: Pulmonary permeability in controls and patient with Crohn's disease. The half time clearance of ${ }^{99 \mathrm{~m}} \mathrm{Tc}$ $D T P A$ from lung to blood $\left(t_{1} L L B\right)$ is expressed in minutes.

was used for correlation. $p$ Values of less than 0.05 were considered significant.

\section{Results}

\section{PULMONARY PERMEABILITY}

The clearance rate from lung to blood of inhaled ${ }^{99 \mathrm{~m}}$ Tc-DTPA expressed as $\mathrm{t} 1 / 2$ lung to blood was decreased - that is, pulmonary permeability increased - in the whole group of patients with Crohn's disease as compared with controls $(45 \cdot 5$ minutes (8-160) $v 85$ minutes (34-130) $(\mathrm{p}<0.003)$ (Fig 1). Fifteen of 22 patients with Crohn's disease showed an increased pulmonary permeability, that is, $\mathrm{t} 1 / 2 \mathrm{LB}<58 \cdot 3 \%$ (mean - SD of controls). When analysed separately only patients with active Crohn's disease $(n=15)$ were found to have an increased pulmonary permeability $v$ controls (42 minutes $(8-160) v 85$ minutes $(34-130) \quad(p<0 \cdot 0025))$. Pulmonary permeability did not differ significantly between patients with quiescent Crohn's disease (62 minutes (40-120)) and controls and between patients with active and quiescent Crohn's disease. Among patients with active Crohn's disease, six were studied again when quiescent and their pulmonary permeability did not differ significantly (Fig 2).

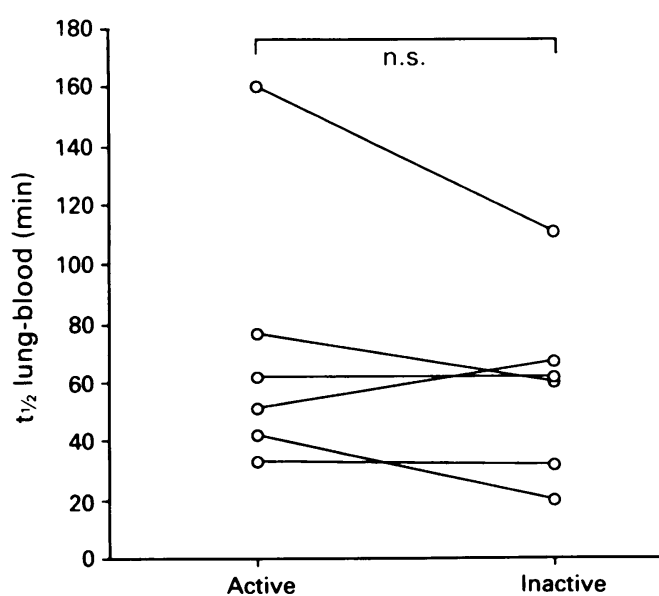

Figure 2: Pulmonary permeability in six patients with Crohn's disease studied when active and inactive - one to seven months later. The half time clearance of ${ }^{99 \mathrm{~m}} T_{c}-D T P A$ from lung to blood $(t, L B)$ is expressed in minutes.

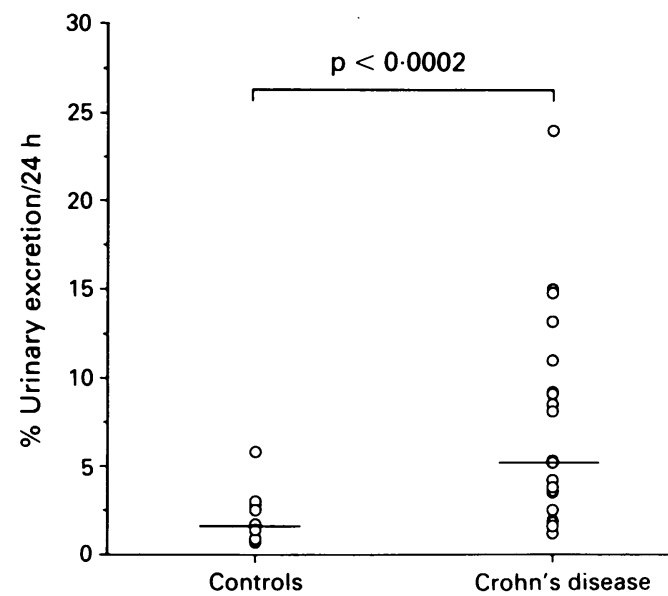

Figure 3: Intestinal permeability in controls and patients with Crohn's disease. The 24 hour urinary excretion of ${ }^{51} \mathrm{Cr}$ -

EDTA is expressed as the percentage of the total ingested dose.

\section{INTESTINAL PERMEABILITY}

Intestinal permeability was increased in the whole group of Crohn's disease patients as compared with controls $(5 \cdot 25 \%(1 \cdot 2-24) v 1 \cdot 7 \%$ $(0 \cdot 65-5 \cdot 75)(\mathrm{p}<0 \cdot 0002))($ Fig 3$)$. When analysed separately both patients with active and inactive Crohn's disease were found to have an increased intestinal permeability $v$ controls $(8 \cdot 1 \%(1 \cdot 6-24)$ $v 1.7 \%(0.65-5.75)(\mathrm{p}<0.0001))$ and $(3.5 \%$ $(1 \cdot 2-9 \cdot 2) v 1 \cdot 7 \%(0 \cdot 65-5 \cdot 75)(\mathrm{p}=0 \cdot 05))$ respectively. Among the patients with active Crohn's disease, six were studied again when quiescent and their intestinal permeability decreased significantly $(\mathrm{p}<0.04)$ (Fig 4$)$.

\section{CORRELATION DATA}

No correlation was found between pulmonary permeability values and intestinal permeability, Crohn's Disease Activity Index, biological and nutritional parameters, treatment received (particularly steroids) and whether or not there were active anal Crohn's disease or systemic manifestations.

BRONCHOALVEOLAR LAVAGE

The results of the bronchoalveolar lavage and the

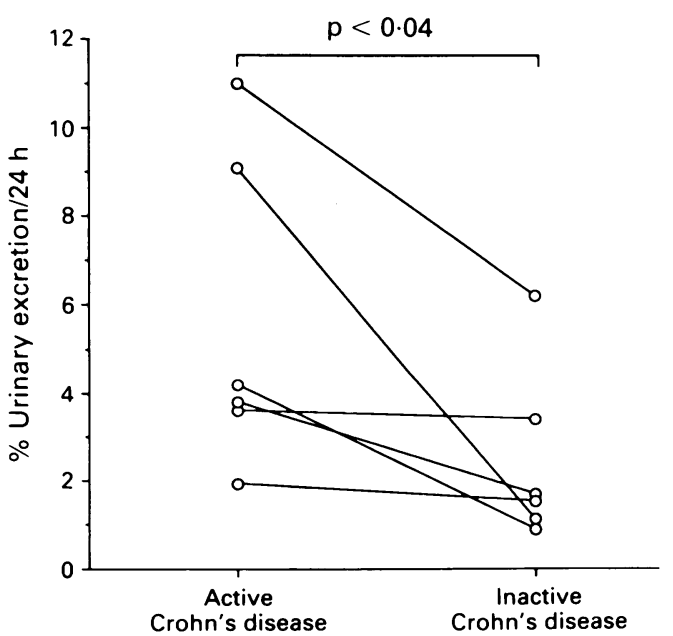

Figure 4: Intestinal permeability in six patients with Crohn's disease studied when active and inactive - one to seven months later. The 24 hour urinary excretion of ${ }^{51} \mathrm{Cr}-E D T A$ is expressed as the percentage of the total ingested dose. 
TABLE II Results of bronchoalveolar lavage and pulmonary permeability values in six patients with active Crohn's disease

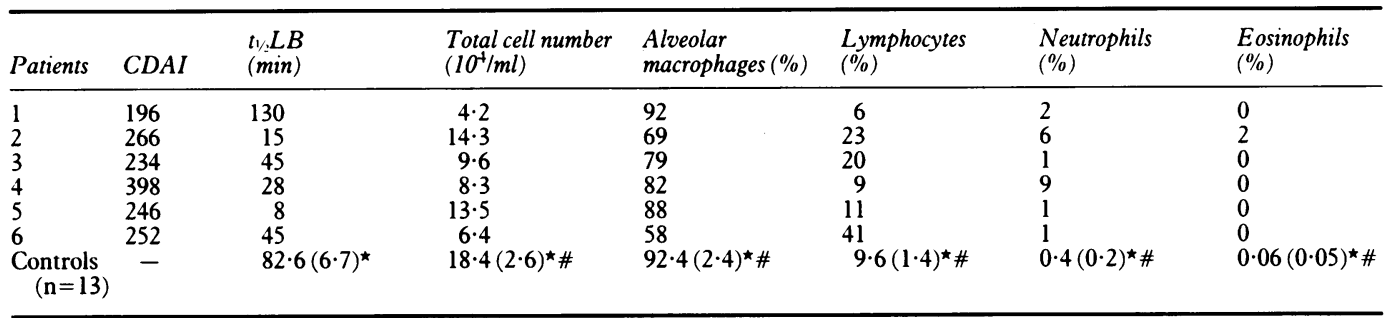

${ }^{\star}$ Results (mean (SEM)) were obtained from 13 healthy nonsmokers and \# previously published. ${ }^{28}$

pulmonary permeability values in six patients with active Crohn's disease are given in Table II. One patient (patient 1) with normal pulmonary permeability had normal bronchoalveolar lavage values. Five patients of six had an increased pulmonary permeability - that is, $\mathrm{t} 1 / 2 \mathrm{LB}<58.3 \%$ (mean-SD of controls); four of these five had abnormal bronchoalveolar lavage values, including one neutrophilic alveolitis (patient 4), two lymphocytic alveolitis (patients 3 and 6), and one associated lymphocytic and neutrophilic alveolitis (patient 2). Finally all patients with abnormal bronchoalveolar lavage values had an increased pulmonary permeability.

\section{Discussion}

Using measurement of pulmonary ${ }^{99 \mathrm{~m}} \mathrm{Tc}$-DTPA clearance, we have shown that pulmonary permeability was significantly increased in Crohn's disease as a whole. Our technique has previously allowed to detect an abnormally raised pulmonary permeability in patients who were cigarette smokers ${ }^{30}$ and in patients with interstitial lung disease..$^{23-253132}$ In contrast, intestinal permeability was increased in Crohn's disease but decreased with the disease activity as previously described. ${ }^{11} 1333$

Those results are not in accordance with Robertson $e a^{3+}$ who reported that patients with inflammatory bowel disease had normal pulmonary permeability as compared with healthy controls. This difference might be because in Robertson's study, pulmonary permeability was measured in a whole group of patients with inflammatory bowel disease (not distinguishing between Crohn's disease and ulcerative colitis) whereas our study only deals with patients with Crohn's disease.

The relationship between pulmonary permeability and Crohn's disease activity is not yet clearly elucidated. On one hand when patients with active and inactive disease were compared with controls, it was only those with active Crohn's disease that have increased pulmonary permeability; those with inactive disease did not differ from controls. On the other hand when six patients with active Crohn's disease were treated and apparently switched to inactive disease, it did not appear to change their pulmonary permeability. This may be related to some confusion over what is active and what is inactive when disease activity is assessed by clinical indexes such as Crohn's Disease Activity Index.

Several mechanisms could account for increased pulmonary permeability in Crohn's disease. Our data support a link between increased pulmonary permeability in patients with Crohn's disease and the presence of an alveolitis. In pulmonary interstitial disease, increased pulmonary permeability has been associated with the presence of such an alveolitis ${ }^{23-25} 32$ which has been demonstrated in $50 \%$ of patients with Crohn's disease. ${ }^{1921}$ In our study, four of six patients exhibited a subclinical alveolitis as judged by an increased number of immune and inflammatory cells found in their bronchoalveolar lavage and all but one (patient 1) had an increased pulmonary permeability. One patient with a marked increased pulmonary permeability, however, had normal bronchoalveolar lavage values (patient 5). Such a discrepancy between pulmonary permeability and bronchoalveolar lavage has been previously put forward by Harrison et al in patients with systemic sclerosis and normal chest radiograph..$^{35}$ The link between alveolitis and increased pulmonary permeability is not established, however. Diethylene triamine pentacetate is believed to cross the alveolocapillary membrane through intercellular junctions. ${ }^{36}$ Increased permeability of lung epithelium to DTPA might be the consequence of an in vivo oxydation of ${ }^{99 \mathrm{~m}} \mathrm{Tc}$ DTPA to ${ }^{99} \mathrm{TcO}_{4^{-}}$(which has a faster $\mathrm{t}_{1 / 2}$ lung to blood than ${ }^{99 \mathrm{~m}}$ Tc-DTPA) by alveolar inflammatory cells. ${ }^{31}$ Previous in vitro study clearly showed the production of free pertechnate $\left({ }^{99} \mathrm{TcO}_{4^{-}}\right)$when ${ }^{99 \mathrm{~m}} \mathrm{Tc}$-DTPA was incubated with activated neutrophils ${ }^{37}$ presumably as a result of the action of reactive free radicals. This mechanism may occur in vivo as in Crohn's disease macrophages are in an activated state and spontaneously release increased amounts of reactive oxygen species. $^{29}$ Alternatively, increased pulmonary permeability could result from a direct harmful effect on intercellular alveolar junctions of active oxygen species released by activated alveolar macrophages. ${ }^{29}$

Other mechanisms for increased pulmonary permeability are possible on theoretical grounds. First, increased pulmonary permeability in Crohn's disease might be the consequence of an inhaled allergen and result from a non-specific inflammation preceding the development of an immune disorder. Bourke et al reported that asymptomatic bird fanciers (with or without antibodies against pigeon gamma globulin) exhibited an increased rate of lung to blood clearance of ${ }^{99 m}$ Tc-DTPA. ${ }^{32}$ In this regard, recent studies reporting an increased prevalence of serum antibodies reactive with Saccharomyces cerevisiae (baker's yeast) in Crohn's disease suggest that Crohn's disease could be a manifestation of immunological hypersensitivity to an environmental antigen. ${ }^{38}{ }^{39}$ Second, increased pulmonary permeability may be caused by 
stretching of intercellular junction by granulomas. This has been suggested by Thunberg et al for explaining increased pulmonary permeability in sarcoidosis with radiological involvement of the lung. ${ }^{2+}$ This hypothesis seems unlikely, however, because granulomatous involvement of the lungs is rare in Crohn's disease $^{+0}$ and as all our patients had normal chest radiographs. Finally, increased pulmonary permeability may be a primary abnormality. This hypothesis fits wcll with the fact that in our study, increased pulmonary permeability was not dramatically influenced by disease activity. Increased pulmonary permeability might then be part of a more generalised defect of epithelial permeability in Crohn's disease such as previously evoked by Hollander et al who showed that intestinal permeability was increased not only in patients with Crohn's disease but also in their healthy relatives. ${ }^{5}$ Whether this defect results from a primary genetic susceptibility or from the effects of environmental factors 12173839 is still unknown.

This work was supported, in part, by Université de Lille II and by INSERM (CJF 90-06). This work was presented, in part, at the Autumn Meeting of The British Society of Gastroenterology 27 29 September 1989, Dublin (Gut [Abstract] 1989; 30: A 1502)

We would like to acknowledge the assistance of Dr J C Paris

$\mathrm{R}$ Collet and Dr X Lesage who incorporated patients in this study.

1 Kirsner JB, Shorter RG. Recent developments in 'nonspecific' inflammatory bowel disease. 1. $N$ Engl f Med 1982; 306: 775-85.

2 Kirsner JB, Shorter RG. Recent developments in 'nonspecific' inflammatory bowel disease. 2. N Engl F Med 1982; 306 837-48.

3 Jewell DP, Patel C. Immunology of inflammatory bowel disease. S cand $\mathcal{F}$ Gastroenterol 1985; 20 (suppl 114): 119-26 Shorter RG, Huizenga KA, Spencer RJ. A working hypothesi for the etiology and pathogenesis of nonspecific inflammafor the etiology and pathogenesis of nonspecific in

tory bowel disease. Am F Dig Dis 1972; 17: 1024-31.
5 Hollander D, Vadheim CM, Brettholz E, Petersen GM Delahunty T, Rotter JI. Increased intestinal permeability in patients with Crohn's disease and their healthy relatives possible etiological factor. Ann Intern Med 1986; 105: 883-5.

6 Katz KD, Hollander D, Vadheim CM, McElree C, Delahunt $\mathrm{T}$, Dadufalza VD, et al. Intestinal permeability in patients with Crohn's disease and their healthy relatives. Gastroenterology 1989; 97: 927-31.

7 Pironi L, Miglioli M, Ruggeri E, Levorato M, Dallasta MA Corbelli $\mathrm{C}$, et al. Relationship between intestinal permeability to ${ }^{51} \mathrm{Cr}$-EDTA and inflammatory activity in asymptomatic patients with Crohn's disease. Dig Dis Sci 1990; 35: matic p.

8 Bjarnason I, O'Morain C, Levi AJ, Peters TJ. Absorption of ${ }^{1}$ Chromium-labeled ethylenediamineteraacetate in inflammatory bowel disease. Gastroenterology 1983; 85: 318-22.

9 Ukabam SO, Clamp JR, Cooper BT. Abnormal smal intestinal permeability to sugars in patients with Crohn's disease of the terminal ileum and colon. Digestion 1983; 27 $70-4$.

10 Casellas F, Aguade S, Soriano B, Accarino A, Molero J, Guarner L. Intestinal permeability to ${ }^{99 \mathrm{~m}} \mathrm{Tc}$ diethylenetriaminopentaacetic acid in inflammatory bowel disease. Am F Gastroenterol 1986; 81: 767-70.

11 Jenkins RT, Chem C, Jones DB, Goodacre RL, Collins SM, Coates G, et al. Reversibility of increased intestinal permeability to ${ }^{51} \mathrm{Cr}$-EDTA in patients with gastrointestinal ability to ${ }^{51} \mathrm{Cr}$-EDTA in patients with gastrointestinal

12 Sanderson IR, Boulton P, Menzies I, Walker-Smith JA Improvement of abnormal lactulose-rhamnose permeability in active Crohn's disease of the small bowel by elementa diet. Gut 1987; 28: 1073-6.

13 Jenkins RT, Ramage JK, Brian-Jones D, Collins SM, Goodacre RL, Hunt RH. Small bowel and colonic permeability to ${ }^{51} \mathrm{Cr}$-EDTA in patients with active inflammatory bowel disease. Clin Invest Med 1988; 11: 151-5.

14 Resnick RH, Royal H, Marshall W, Barron R, Werth T. Intestinal permeability in gastrointestinal disorders. Use of oral ${ }^{99 \mathrm{~m}}$ Tc-DTPA. Dig Dis Sci 1990; 35: 205-11
15 Olaison G, Leandersson P, Sjodahl R, Tagesson C. Intestinal permeability to polyethyleneglycol 600 in Crohn's disease. Peroperative determination in a defined segment of the small intestine. Gut 1988; 29: 196-9.

16 Ainsworth M, Eriksen J, Waever Rasmussen J, Schaffalitzky De Muckadell OB. Intestinal permeability of ${ }^{51} \mathrm{Cr}$-labelled ethylenediaminetetraacetic acid in patients with Crohn' disease and their healthy relatives. Scand $\mathcal{F}$ Gastroentero 1989; 24: 993-8.

17 Irvine EJ, Collins SM. ${ }^{51} \mathrm{Cr}$-EDTA permeability: a marker of environmental and genetic risk in Crohn's disease (CD) Gastroenterology 1990; 98: Al17.

18 Teahon K, Smethurst P, Rideout JM, Levi J, Bjarnason I. Intestinal permeability in patients with Crohn's disease and their 1st degree relatives. Gastroenterology 1991; 100: A256.

19 Wallaert B, Colombel JF, Tonnel AB, Bonnier Ph, Cortot A Paris JC, et al. Evidence of lymphocyte alveolitis in Crohn's disease. Chest 1985; 87: 363-6.

20 Bonniere Ph, Wallaert B, Cortot A, Marchandise X, Riou Y, Tonnel AB, et al. Latent pulmonary involvement in Crohn's disease: biological, functional, bronchoalveolar lavage and scintigraphic studies. Gut 1986; 27: 919-25.

21 Smiejan JM, Cosnes J, Chollet-Martin S, Soler P, Basset FM Le Quintrec Y, et al. Sarcoid-like lymphocytosis of the lowe respiratory tract in patients with active Crohn's disease. Ann Intern Med 1986; 104: 17-21.

22 Keogh BA, Hunninghake GW, Line BR, Crystal RG. Th alveolitis of pulmonary sarcoidosis: evaluation of natural history and alveolitis dependant changes in lung function. Am Rev Respir Dis 1983; 128: 256-65.

23 Rinderknecht J, Shapiro L, Krauthammer M, Taplin G Wasserman $\mathrm{K}$, Uszler $\mathrm{M}$, et al. Accelerated clearance of small solutes from the lungs in interstitial lung disease. Am Rev Respir Dis 1980; 121: 105-17.

24 Thunberg S, Larsson K, Eklund A, Blaschke E. ${ }^{99 \mathrm{~m}}$ Tc-DTPA clearance measured by a dual head camera in healthy clearance measured by a dual head camera in healthy 15: $71-7$.

25 Chopra SK, Taplin GV, Tashkin DP, Elam D. Lung clearance of soluble radioaerosols of different molecules weights in systemic sclerosis. Thorax 1979; 34: 63-7.

26 Meignan M, Rosso J, Robert R. Lung epithelial permeability to aerosolized solutes: relation to position. $\mathcal{F}$ Apply Physio 1987; 62: 902-11.

27 Coates G, O'Brodovitch $\mathbf{H}$. Extrapulmonary radioactivity in lung permeability measurements. F Nucl Med 1987; 28: 903

28 Wallaert B, Aerts C, Bart F, Hatron PY, Dracon M, Tonnel AB, et al. Alveolar macrophages dysfunction in systemic lupus erythematosis. Am Rev Respir Dis 1987; 136: 293-7.

29 Wallaert B, Aerts $\mathrm{C}$, Bonniere $\mathrm{Ph}$, Cortot $\mathrm{A}$, Tonnel $\mathrm{AB}$ Paris JC, et al. Superoxide anion generation by alveolar macrophages in Crohn's disease. $N$ Engl F Med 1985; 312 : 444.

30 Jones JG, Lawler P, Crawley JCW, Minty BD, Hulands G, Veall $N$. Increased alveolar epithelial permeability in cigarette smokers. Lancet 1980; i: 66-8.

31 O'Brodovitch H, Coates G. Pulmonary clearance of ${ }^{99 \mathrm{~m}^{\prime} \mathrm{Tc}}$ DTPA. Lung 1987; 165: 1-16.

32 Bourke S, Bonham SW, McKillop JK, Boyd G. Clearance of ${ }^{99} \mathrm{~m}$ Tc-DTPA in Pigeon Fancier's hypersensitivity pneumonitis. Am Rev Respir Dis 1990; 142: 1168-71.

33 O'Morain CA, Chervu LR, Milstein DM, Das KM Chromium 51 ethylenediaminetetraacetate test: a useful test in the assessment of inflammatory bowel disease. Lab Clin Med 1986; 108: 430-5.

34 Robertson DAF, Taylor N, Sidhu H, Britten A, Smith CL Holdstock G. Pulmonary permeability in coeliac disease an inflammatory bowel disease. Digestion 1989; 42: 98-103.

35 Harrison NK, Glanville AR, Strickland B, Haslam PL Corrin $\mathrm{B}$, Addis $\mathrm{BJ}$, et al. Pulmonary involvement in systemic sclerosis: the detection of early changes by thin section CT scan, bronchoalveolar lavage and $99 \mathrm{mTc}$-DTPA clearance. Respir Med 1989; 83: 403-14.

36 Jones JG, Minty BD, Royston D. The physiology of leaky lungs. Br F Anaesth 1982; 54: 705-21.

37 Nolop KB, Maxwell DL, Fleming JS, Braude S, Hughes JMB, Royston D. A comparison of ${ }^{99 \mathrm{~m} T c-D T P A}$ and $13 \mathrm{~m}$ In-DTPA aerosol clearances in humans. Effect of smoking, hyperinflation, and in vitro oxydation. Am Rev Smoking, hyperinflation, and

38 Barnes RMR, Allan S, Taylor-Robinson CH, Finn R, Johnson PM. Serum antibodies reactive with Saccharomyces cerevisia in inflammatory bowel disease: is IgA antibody a market for Crohn's disease? Int Arch Allergy Appl Immunol 1990; 92: 9 15 .

39 Main J, McKenzie H, Yaeman GR, Kerr MA, Robson D Pennington CR, et al. Antibody to Saccharomyces cerevisiae (baker's yeast) in Crohn's disease. BMF 1988; 297: 1105-6.

40 Lemann M, Messing B, D'Agay F, Modigliani R. Crohn's disease with respiratory tract involvement. Gut 1987; 28 : 1669-72. 